\title{
Patterns of complementary and alternative medicine use among patients undergoing cancer treatment
}

J. CORNER, BSC, PHD, RN, School of Nursing and Midwifery, University of Southampton, Highfield, Southampton, J. YARDLEY, SRN, HVCert, MA (ED), School of Nursing and Midwifery, University of Southampton, Highfield, Southampton, E.J. MAHER, FRCP, FRCR, Supportive Oncology Research Team, Lynda Jackson Macmillan Centre, Mount Vernon Cancer Centre, Northwood, Middx, L. ROFFE, bsc (Hons), School of Nursing and Midwifery, University of Southampton, Highfield, Southampton, T. YOUNG, BSC, Supportive Oncology Research Team, Lynda Jackson Macmillan Centre, Mount Vernon Cancer Centre, Northwood, Middx, S. MASLIN-PROTHERO, RN, RM, DIPN, MSC, PHD, School of Nursing and Midwifery, Keele University, Stoke-on-Trent, Staffordshire, C. GWILLIAM, ва (ноNs), Supportive Oncology Research Team, Lynda Jackson Macmillan Centre, Mount Vernon Cancer Centre, Northwood, Middx, J. HAVILAND, Msc, ICR-CTSU, Institute of Cancer Research, Sutton, Surrey, \& G. LEWITH, MD, FRCP, Complementary Medicine Research Unit, Primary Medical Care, School of Medicine, University of Southampton, Aldermoor Health Centre, Southampton, UK

CORNER J., YARDLEY J., MAHER E.J., ROFFE L., YOUNG T., MASLIN-PROTHERO S., GWILLIAM C., HAVILAND J. \& LEWITH G. (2009) European Journal of Cancer Care 18, 271-279

Patterns of complementary and alternative medicine use among patients undergoing cancer treatment

This study aimed to assess the prevalence of complementary and alternative medicine (CAM) use in a representative cancer population prior to and within 6 months of diagnosis. A total of 304 newly diagnosed cancer patients from two UK cancer centres completed a postal survey. Of them, 100 patients $(32.9 \%)$ used CAM before their cancer diagnosis, 59 of these CAM users continued post diagnosis. Twenty-nine individuals who had not used CAM before began to use it after their cancer diagnosis, creating a total of 88 (28.9\%) CAM users in this sample. Reasons for not using CAM included lack of interest, lack of information or endorsement from professionals and satisfaction with conventional care. For those using CAM before diagnosis but not afterwards, the most common reason was a lack of expert guidance on what was safe to use. The use of CAM medicines bought from health food and other retail outlets was high. Complementary and alternative medicine use in cancer patients is common and demonstrates a complex pattern, but CAM use is not significantly greater than in the general population. Some patients purchase CAM medicines without seeking medical advice, thus risking drug interactions. Research to generate information on safety and efficacy of CAM is required.

Keywords: complementary medicine, alternative medicine, cancer, cancer treatment.

\section{INTRODUCTION}

Complementary and alternative medicines (CAM) are widely used among the general population, indeed their

Correspondence address: JL Corner, Professor of Cancer and Palliative Care, School of Nursing and Midwifery, University of Southampton, Highfield, Southampton, SO17 1BJ, UK (e-mail: j.l.corner@soton.ac.uk).

Accepted 21 November 2007

DOI: $10.1111 / \mathrm{j} .1365-2354.2007 .00911 . \mathrm{x}$

European Journal of Cancer Care, 2009, 18, 271-279 use is increasing. Surveys conducted in the UK, the US and in Australia indicate that between $10 \%$ and $25 \%$ of the population use CAM each year, and $50 \%$ of the population use CAM at some point in their lifetime (Eisenberg et al. 1993; Fisher \& Ward 1994; MacLennan et al. 1996). A recent population-based survey in England (Thomas et al. 2001) found that $14 \%$ of adults had visited one of eight specified complementary therapists, and $28 \%$ of adults surveyed had used a therapy or over the counter remedy in the previous 12 months. Only $10 \%$ of contacts 
with CAM therapists were through the UK National Health Service (NHS), the remainder being paid for through out-of-pocket expenditure (Thomas et al. 2001). The prevalence of CAM use has led to questions as to the efficacy and safety of this largely unregulated form of health care, as well as whether such therapies should be integral to formal systems of health care such as the NHS.

Studies of patients with cancer have suggested a higher use of CAM than the normal population (Cassileth et al. 1984; Downer et al. 1994; Rees et al. 2000; Sollner et al. 2000; Paltiel et al. 2001; Malassiotis 2005). A systematic review of 26 studies from 13 countries revealed that between $7 \%$ and $63 \%$ of patients with cancer use CAM with a median of $31 \%$ for the patients sampled (Ernst \& Cassileth 1998). However, these studies involve selective patient samples and differing definitions of CAM, distorting true estimates of prevalence of CAM use among people with cancer. This study set out to explore the ways in which CAM is used by a nationally representative group of newly diagnosed cancer patients undergoing active conventional treatment.

\section{METHODS}

This was a questionnaire-based cross-sectional epidemiological study. Patients were sampled on a quota basis, to ensure that the distribution of cancer sites mirrored figures from National Cancer Statistics 2001 (Cancer UK 2001). Data were collected from a sample of recently diagnosed (within 6 months) patients attending two cancer treatment centres in the South of England. Local research ethics approval was given at both study centres (Southampton and South-west Hampshire (052/03/w) and West Hertfordshire Hospitals NHS Trust (EC2003-34)). Initially, study centre 1 was refused permission for the researchers to approach patients directly and discuss the study, so questionnaires were distributed in sealed envelopes by reception staff as patients arrived for treatment. After 3 months of low recruitment, a case was made to the local research ethics committee (LREC) that relying on reception staff to distribute the sealed envelopes led to the situation where the research team were unable to know whether or not patients had been approached and, therefore, it was unclear whether the low recruitment was due to patients declining to take part or that they had been overlooked by busy clinic staff. As a result, the restriction was removed by the LREC. Both committees specified that no contact was allowed with patients after distribution of the questionnaire and no reminders could be sent. The stringency applied by both LRECs meant that recruitment was lower than would have been the case if the research team had been allowed to approach patients after questionnaire distribution and to follow-up non-response. All patients provided written informed consent.

Those recruited completed a postal questionnaire including closed and open-ended questions about their use of CAM both before and since receiving a cancer diagnosis. The questionnaire was developed and piloted following a review of published questionnaires including estimating CAM use, and was based on both the House of Lords Science and Technology Select Committee (2000) definition of CAM and Thomas et al.'s (2001) questionnaire-based survey.

Patient characteristics and frequencies of CAM use before and after diagnosis were tabulated. The Townsend Material Deprivation Index (Townsend et al. 1988) (based on patients' postcode) was used as a measure of socioeconomic status, and categorized by quintiles within the study population. As distribution of time from diagnosis to screening was skewed, data were presented using medians and interquartile ranges (IQR). In order to determine which patient characteristics predicted CAM use before and after diagnosis, factors were first investigated in univariate analyses and tested using the $\chi^{2}$ test (or $\chi^{2}$ test for trend where appropriate), the $t$-test for age and the non-parametric Mann-Whitney test for time from diagnosis. Forward stepwise logistic regression analysis was then carried out, including all of the patient characteristics to determine which factors remained significant independent predictors for CAM use before and after diagnosis.

Analysis of open-ended questions relating to the reasons why patients used or did not use CAM used a contentanalysis approach. Statements recorded on questionnaires were collated and grouped into like categories, where they were summarized and then described thematically. Counts of the number of patients with similar responses were made to identify the most commonly occurring themes.

\section{RESULTS}

A total of 304 patients returned their questionnaire by post. Over the study period, and across both centres, this represents $51 \%$ of all patients approached for the study. However, the initial response rate at study centre 1 was very low due to LREC restrictions, but once these were removed, the response rate approached that of study centre 2 at $65 \%$. As with other such surveys, patients were less likely to return questionnaires if they were male, had advanced disease and did not have breast cancer. Demographic data about the patient sample are contained in Table 1 and were similar in both centres, but with a lower 
Table 1. Demographic and clinical characteristics

\begin{tabular}{|c|c|c|}
\hline Demographic/clinical characteristic & \multicolumn{2}{|l|}{ Total $(\%) n=304$} \\
\hline \multicolumn{3}{|l|}{ Age (years) } \\
\hline$<50$ & $64(21.1)$ & \\
\hline $50-59$ & $71(23.4)$ & \\
\hline $60-69$ & $82(27.0)$ & \\
\hline$\geq 70$ & $85(28.0)$ & \\
\hline Unknown & $2(0.7)$ & \\
\hline Mean (SD) & $60.0(13.5)$ & \\
\hline \multicolumn{3}{|l|}{ Gender } \\
\hline Female & $169(55.6)$ & \\
\hline Male & $134(44.1)$ & \\
\hline Unknown & $1(0.3)$ & \\
\hline \multicolumn{3}{|l|}{ Marital status } \\
\hline Married/re-married/living with partner & $221(72.7)$ & \\
\hline Single/widowed/separated/divorced & $80(26.3)$ & \\
\hline Unknown & $3(1.0)$ & \\
\hline \multicolumn{3}{|l|}{ Highest educational qualification } \\
\hline Less than compulsory school education & 42 (13.8) & \\
\hline Compulsory school education & 97 (31.9) & \\
\hline Post compulsory school education & $83(27.3)$ & \\
\hline University/postgraduate level & $70(23.1)$ & \\
\hline Unknown & $12(3.9)$ & \\
\hline \multicolumn{3}{|l|}{ Paid work } \\
\hline Retired & $151(49.7)$ & \\
\hline Not working at present & $34(11.2)$ & \\
\hline Yes & $116(38.2)$ & \\
\hline Unknown & $3(1.0)$ & \\
\hline \multicolumn{3}{|l|}{ Recruitment clinic } \\
\hline Chemotherapy & $142(46.7)$ & \\
\hline Radiotherapy & $149(49.0)$ & \\
\hline Other & $9(3.0)$ & \\
\hline Unknown & $4(1.3)$ & \\
\hline Cancer site & Required ${ }^{*}$ & Actual \\
\hline Breast & $46(15 \%)$ & $76(25.0)$ \\
\hline Prostate & $27(9 \%)$ & $42(13.8)$ \\
\hline Large bowel & $40(13 \%)$ & $42(13.8)$ \\
\hline Lung & $43(14 \%)$ & $22(7.2)$ \\
\hline Head and neck & $9(3 \%)$ & $11(3.6)$ \\
\hline Bladder & $15(5 \%)$ & $10(3.3)$ \\
\hline Oesophagus & $9(3 \%)$ & $8(2.6)$ \\
\hline Non-Hodgkin's Lymphoma & $9(3 \%)$ & $7(2.3)$ \\
\hline Pancreas & $9(3 \%)$ & $4(1.3)$ \\
\hline Stomach & $12(4 \%)$ & $3(1.0)$ \\
\hline Unknown & $4(1.3)$ & \\
\hline Other & $85(28 \%)$ & $75(24.7)$ \\
\hline \multicolumn{3}{|l|}{ Stage } \\
\hline I & $16(5.3)$ & \\
\hline II & $64(21.0)$ & \\
\hline III & $48(15.8)$ & \\
\hline IV & $34(11.2)$ & \\
\hline Unknown & $142(46.7)$ & \\
\hline \multicolumn{3}{|l|}{ Metastases } \\
\hline Yes & $34(11.2)$ & \\
\hline No & $153(50.3)$ & \\
\hline Unknown & $117(38.5)$ & \\
\hline Time from diagnosis to screening (months) & $3.0(2.2-4.2)$ & \\
\hline Median (IQR) [range] & {$[0.1-9.9]$} & \\
\hline
\end{tabular}

${ }^{\star}$ Based on national incidence.

$\mathrm{IQR}$, interquartile range.

education level of patients from study centre $2(P=0.007)$. The mean age of the patients was 60 years, $55.6 \%$ were female, $72.7 \%$ were married (or living with a partner). The quota sample was achieved for most of the less common cancer sites (e.g. bladder, non-Hodgkins lymphoma, head and neck), but some of the most frequent sites were overrepresented (breast, prostate), while others were underrepresented (lung), particularly in centre 1.

\section{PATTERNS OF CAM USE}

Four patterns of CAM use were identified: patients who used CAM before diagnosis and continued to do during cancer treatment, patients who used CAM before diagnosis but stopped using CAM during treatment; patients who used CAM for the first time following diagnosis; and finally patients who did not use CAM at any time.

\section{CAM use before diagnosis}

One hundred patients $(32.9 \%)$ reported that they had used CAM before their diagnosis $9.9 \%$ often and $23.0 \%$ sometimes) (Table 2). This reflects the proportion of the general population using CAM found in other studies; 33 (10.3\%) reported purchasing over-the-counter (OTC) medicines (Eisenberg et al. 1993; Fisher \& Ward 1994; MacLennan et al. 1996; Sollner et al. 2000; Thomas et al. 2001). A wide variety of CAM therapies were reported, the most common being aromatherapy $(28.0 \%)$, reflexology $(26.0 \%)$, chiropractic medicine $(24.0 \%)$, acupuncture $(23.0 \%)$, herbal medicine $(22.0 \%)$ and yoga $(20.0 \%)$. The median number of therapies was two (IQR 1-4, range 1-10). Of the 100 patients who had used CAM before diagnosis, $45.0 \%$ had disclosed their CAM use to their general practitioner (GP), and 59 of these patients continued to use CAM after their diagnosis.

\section{Factors predicting CAM use before diagnosis}

Patients who used CAM before their diagnosis of cancer were more likely to be younger $(P=0.05)$, female $(P=$ $0.006)$ and with a higher educational level $(P<0.001)$ (Table 3). There was a non-significant difference between numbers using CAM before diagnosis in study centre 1 $(36.5 \%)$ compared with study centre $2(29.5 \%)(P=0.27)$. Regression analysis including all the factors in Table 3 showed that gender $(P=0.007)$ and education $(P<0.001)$ were the only significant independent predictors of CAM use before diagnosis. Marital, socio-economic and employment status did not predict pre-diagnostic use.

\section{CAM use following diagnosis}

Eighty-eight $(28.9 \%)$ reported CAM use after their diagnosis; 29 of these individuals had not used CAM before. A 
Table 2. Complementary and alternative medicine (CAM) use before diagnosis of cancer

\begin{tabular}{|c|c|}
\hline & Total $(\%)$ \\
\hline Used CAM before diagnosis & $n=304$ \\
\hline Often & $30(9.9)$ \\
\hline Sometimes & $70(23.0)$ \\
\hline Never & $200(65.8)$ \\
\hline Unknown & $4(1.3)$ \\
\hline Which CAMs used ${ }^{\star}$ & $n=100$ \\
\hline Aromatherapy & $28(28.0)$ \\
\hline Reflexology & $26(26.0)$ \\
\hline Chiropractic & $24(24.0)$ \\
\hline Acupuncture & $23(23.0)$ \\
\hline Herbal medicine & $22(22.0)$ \\
\hline Yoga & $20(20.0)$ \\
\hline Homeopathy & $18(18.0)$ \\
\hline Bach/other flower remedies & $18(18.0)$ \\
\hline Osteopathy & $17(17.0)$ \\
\hline Body work therapies & $16(16.0)$ \\
\hline Other & $14(14.0)$ \\
\hline Nutritional medicine & $9(9.0)$ \\
\hline Counselling & $7(7.0)$ \\
\hline Hypnotherapy & $4(4.0)$ \\
\hline Meditation & $4(4.0)$ \\
\hline Healing & $4(4.0)$ \\
\hline Chinese herbal medicine & $4(4.0)$ \\
\hline Shiatsu & $3(3.0)$ \\
\hline Maharishi Ayurvedic medicine & $2(2.0)$ \\
\hline Ayurvedic medicine & $2(2.0)$ \\
\hline Dowsing & $2(2.0)$ \\
\hline Kinesiology & $2(2.0)$ \\
\hline Anthroposophical medicine & $1(1.0)$ \\
\hline Naturopathy & $1(1.0)$ \\
\hline Traditional Chinese medicine & $1(1.0)$ \\
\hline Crystal therapy & $1(1.0)$ \\
\hline Spiritual & $1(1.0)$ \\
\hline
\end{tabular}

${ }^{\star}$ Percentages add to more than $100 \%$ as more than one CAM could be used.

wide variety of CAM therapies were used, the most common being reflexology $(35.2 \%)$, aromatherapy $(30.7 \%)$ and herbal medicine $(25.0 \%)$ (Table 4$)$. Again, patients tended to use more than one CAM with a median number of two (IQR 1-3, range 1-9).

Of the 88 patients who had used CAM since their diagnosis, $42.0 \%$ had sought help from a CAM practitioner, and $45.5 \%$ had bought OTC medicines. These prevalence figures for OTC remedy use are similar to those observed previously by Werneke et al. (2004). There were no significant differences in patient characteristics between those who did and did not consult practitioners or buy OTC medicines. Of the 40 patients who had bought OTC treatments, in $75 \%$ of cases these were purchased from outlets where pharmacological advice was unlikely to be available, i.e. health food stores $(57.5 \%)$ and supermarkets $(17.5 \%)$, rather than pharmacists $(25 \%)$. Over-the-counter products purchased included nutritional medicines
(48.8\% of the 40 patients) and herbal medicines $(25.6 \%$ of the 40 patients). It is noteworthy that $56 / 88(63.6 \%)$ of the patients used therapies provided by the study centres (aromatherapy, reflexology and counselling). Almost all patients using CAM therapies said that they found them helpful, with only a few patients unsure of their value. Patients found out about CAM from members of their family $(25.0 \%)$ and friends $(28.4 \%)$. Twenty-seven per cent of patients had read about particular therapies and then decided to use them. They also received information about CAM from healthcare professionals, such as doctors $(10 \%)$, nurses $(35.2 \%)$ and 'others' $(12.5 \%)$. Of the 88 patients who had used CAM since diagnosis, 16 (18.2\%) had informed their GP of their CAM use, 29 (33.0\%) had informed their consultant and $42(47.7 \%)$ had also informed a nurse. Twenty-three of the 88 patients $(26.1 \%)$ who had used CAM since their diagnosis had not informed a health professional.

\section{Factors predicting CAM use following diagnosis}

Patients who used CAM following their cancer diagnosis were more likely to be younger, female, with a higher educational level, currently not working, to have breast cancer and to have used CAM before diagnosis (all $P<0.001)$. They were also more likely to have early stage disease $(P=0.009)$ and to perceive their illness to be affecting their day-to-day lives $(P=0.01)$. There were significantly more CAM users at study centre 1 compared with centre $2(P=0.01)$ (Table 5). There were no significant differences in CAM use according to marital status or socio-economic status. Complementary and alternative medicine use before diagnosis $(P<0.001)$, age $(P=0.006)$, gender $(P<0.001)$ and study centre $(P=0.02)$ were independent predictors of CAM use after diagnosis after regression analysis using all factors on Table 5. When CAM use before diagnosis was omitted from the stepwise regression model, significant factors included gender $(P<0.001)$, education $(P=0.003)$, employment $(P=0.01)$ and disease stage $(P=0.03)$.

\section{Comparison between CAM use before and after diagnosis}

Fifty-nine of the 100 patients reporting CAM use before diagnosis used it after diagnosis and 41 did not. Independent predictors of continued CAM use were younger age $(P=0.01)$, female gender $(P=0.001)$ and early-stage disease $(P=0.01)$. Twenty-nine patients who were not using CAM before diagnosis had taken up using CAM. Following regression analysis, the only significant predictor for 
Table 3. Complementary and alternative medicine (CAM) use before diagnosis according to patient characteristics

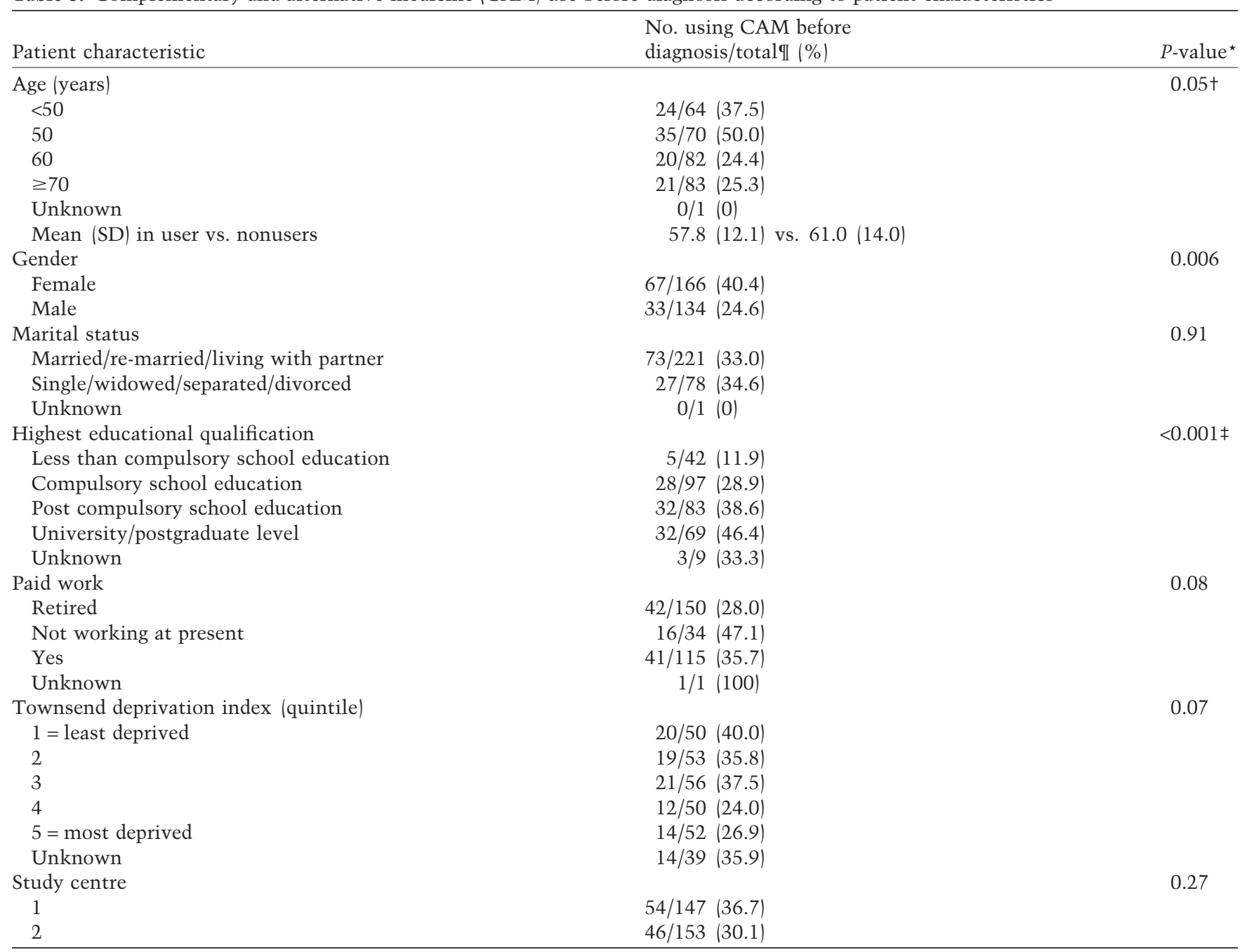

Unknown categories not included in the significance tests.

${ }^{\star} P$-value corresponds to $\chi^{2}$ test unless otherwise specified.

$t$-test.

$\ddagger \chi^{2}$ test for trend.

ICAM use before diagnosis unknown for 4 patients.

previous non-users taking up CAM was early-stage disease $(P=0.02)$.

Reflexology (which was available at both centres), was the most common therapy used before and after diagnosis by older patients, men, those with disease sites other than breast and prostate, and those with less than compulsory education. Herbal medicine and reflexology were the most common therapies used before and after diagnosis by those in the most deprived socio-economic category.

\section{Motivations for using CAM}

In response to open-ended questions about the motivations for using CAM can broadly be categorized as follows: some patients adopted CAM as a strategy to enhance or have an additive effect on conventional treatment, thus improving the chance of cure from cancer. Others used CAM to help cope with the stress of having cancer, to help with feeling more relaxed and in control of the situation; it was also felt that being stressed may make successful treatment less likely or might mean that cancer was more likely to return. Some had used CAM to assist in reducing the side effects of cancer treatment, especially if conventional measures for managing these had failed.

How an individual came to use CAM varied. Whether this was offered in the treatment centre and endorsed by the treatment team appeared to be important in encouraging individuals to use CAM and encouraged individu- 
Table 4. Complementary and alternative medicine (CAM) use after diagnosis of cancer

\begin{tabular}{lc}
\hline & Total $(\%)$ \\
\hline Used CAM after diagnosis & $n=304$ \\
Yes & $88(28.9)$ \\
No & $215(70.7)$ \\
Unknown & $1(0.3)$ \\
CAMs used after diagnosis ${ }^{\star}$ & $n=88$ \\
Reflexology & $31(35.2)$ \\
Aromatherapy & $27(30.7)$ \\
Herbal medicine & $22(25.0)$ \\
Other & $14(15.9)$ \\
Body work therapies & $12(13.6)$ \\
Nutritional medicine & $12(13.6)$ \\
Homeopathy & $10(11.4)$ \\
Meditation & $9(10.2)$ \\
Yoga & $9(10.2)$ \\
Bach/other flower remedies & $9(10.2)$ \\
Counselling & $8(9.1)$ \\
Acupuncture & $6(6.8)$ \\
Healing & $3(3.4)$ \\
Spiritual & $3(3.4)$ \\
Osteopathy & $2(2.3)$ \\
Chinese herbal medicine & $2(2.3)$ \\
Chiropractic & $1(1.1)$ \\
Hypnotherapy & $1(1.1)$ \\
Shiatsu & $1(1.1)$ \\
Maharishi Ayurvedic medicine & $1(1.1)$ \\
Anthroposophical medicine & $1(1.1)$ \\
\hline
\end{tabular}

* Percentages add to more than $100 \%$ as more than one CAM could be used.

als who would not have otherwise considered it to used CAM. In these instances, the fact that CAM was not charged for was significant. Family members, friends and fellow patients also importantly influenced and encouraged the use of CAM. Other individuals with a strong commitment to managing their health themselves sought out particular therapies, and some were prepared to pay for these on an ongoing basis. A small group of individuals had used CAM on a long-standing basis to help with particular health problems, such as back problems, headaches or stress, and they continued to use CAM after their diagnosis.

An important observation from this study is that often there was no direct connection between the particular CAM therapy chosen and the purpose for which it was being used. In other words, patients were not using CAM as a form of specific therapy, mostly, CAM was used for general, non-specific, whole body or system purposes, such as 'boosting the immune system' or 'helping reduce stress'.

\section{Reasons for not using CAM}

In response to open-ended questions about the reasons for not using CAM, low interest in CAM was cited by 54 patients $(25 \%)$ as their main reason for non-use. Patients indicated that they were satisfied with their conventional treatment and confident of the doctor's management of their illness, and therefore did not see the value of any additional treatment. Other reasons included a lack of information about safety and the cost and availability of CAM. The most common reason given for use before diagnosis but not after was a lack of expert guidance on what was safe to use.

\section{DISCUSSION}

This study presents a different picture for CAM use following a diagnosis of cancer than previous published reports (Ernst \& Cassileth 1998; Malassiotis 2005). Nearly half of those who had used CAM in the past did not use CAM after a diagnosis of cancer. However, others who had never previously used CAM started using it. While groups previously associated with CAM use (women, younger people and those with early-stage disease) predominate, this does not mean that other groups are uninterested in using CAM. There was also evidence of use of these therapies prior to diagnosis among those least expected to use CAM, such as older people, men and people living in deprived areas. The most important predictive factor for CAM use is use prior to diagnosis, suggesting that CAM may be part of people's usual self-care rather than a specific strategy to manage cancer.

Reflexology and aromatherapy massage were the most commonly used CAM therapies, and were available as part of the package of care offered in the two cancer treatment settings. Their availability would very probably have reassured patients that these two therapeutic interventions were safe to use during cancer treatment. However, much of the identified CAM use was OTC remedies purchased from health food stores and supermarkets where there will be very limited medical help or guidance on how these products may be best utilized. Supplements, such as garlic and cod liver, have an anticoagulant effect and may interfere with conventional anticoagulant therapies (Fugh-Berman 2000), while Hypericum (St John's Wort), often taken to help with depression, is known to act on the cytochrome P450 system, and may affect the metabolism of some hormones, antibiotics and cytotoxic agents (Izzo \& Ernst 2001). Echinacea interferes with corticosteroid and monoclonal antibody treatments used to treat lymphomas (Jellin et al. 2003). As only $18 \%$ told their GPs and $48 \%$ of patients told their consultants about their CAM use, we consider that this relatively high level of OTC supplement use may expose cancer patients to a risk of drug interaction. 
Table 5. Complementary and alternative medicine (CAM) use after diagnosis according to patient characteristics

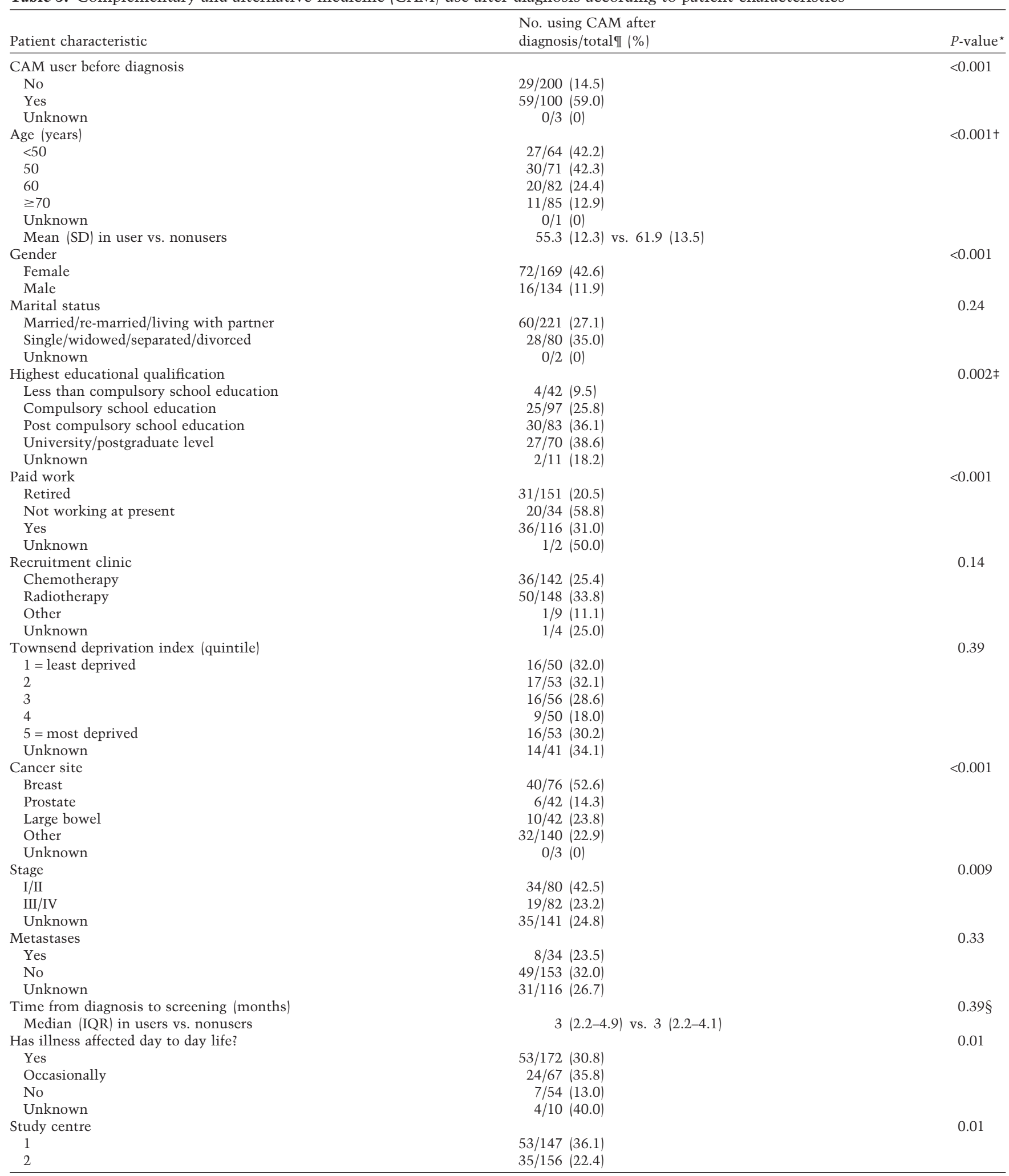

Unknown categories not included in the significance tests.

${ }^{\star} P$-value corresponds to $\chi^{2}$ test unless otherwise specified.

tt-test.

$\neq \chi^{2}$ test for trend.

$\S M a n n-W h i t n e y$ test.

IICAM use after diagnosis unknown for 1 patient. 
The study has limitations. Just over half of patients approached participated in the study. A substantial and significant difference in the interpretation of the new ethics procedures meant that study centre 1 was unable to recruit to full capacity in the initial stages. We suspect that lower response rates may become the norm for future surveys at some centres until there is some national agreement on the interpretation of ethics procedures for surveys. However, in spite of these problems, and our new and unique observations, this study has considerable consistency with previously published data; for instance, CAM use in early breast and prostate cancer is approximately double that for other cancer sites and the prevalence of OTC herbal and supplement use is consistent with previous reports (Werneke et al. 2004). We therefore consider that our low response rate may not be a significant limitation when considering the generalizability of these data to all patients with cancer. Comparison of nonresponders with those responding to the questionnaire suggests that patients with advanced disease and who were male were less likely to participate as with most questionnaire-based supportive care studies in cancer, and therefore results relating to these groups should be interpreted with caution.

\section{CONCLUSIONS}

This is the first study to report the use of CAM among a representative sample of cancer patients attending UK cancer treatment settings. Complementary and alternative medicine use among cancer patients is not substantially greater than has been suggested for the UK population as a whole (Thomas et al. 2001). Previous surveys (Ernst \& Cassileth 1998; Malassiotis 2005) may have overestimated $\mathrm{CAM}$ use as a consequence of their non-representative sampling techniques. However, we can confirm that CAM use among patients undergoing cancer treatment is common, with approximately one-third using CAM, particularly those with early breast cancer. Surprisingly, CAM use in this population is not predicted by socio-economic status. The primary reason for this relatively low CAM use may be concern among patients about what CAM therapies are safe or advisable to use alongside conventional treatment and a clear reluctance to discuss this with their conventional healthcare professionals. Of those who used CAM, less than half of them shared this fact with their oncology treatment team; these disclosure rates are similar to those reported previously (Eng et al. 2001). Those patients who purchased OTC remedies tended to do so from places where no healthcare professional was available to provide medical advice.
This study suggests that there is a need for further research with respect to CAM use among cancer patients in order to generate information for patients about what they may safely use alongside conventional treatment. Over half our respondents decided to use CAM without discussing it with their cancer treatment team, and healthcare professionals involved in managing patients with cancer would do well to consider discussing CAM use with their patients in a supportive and positive manner.

\section{ACKNOWLEDGMENT}

The University of Southampton and Mount Vernon Cancer Centre who received funding from the Department of Health. The views expressed are those of the authors and not necessarily those of the Department of Health. All authors are independent from the Department of Health who commissioned this study.

\section{REFERENCES}

Cancer UK. (2001) UK Cancer Incidence Statistics by Country. Available at: http://info.cancerresearchuk.org/cancerstats/ incidence/site/? a =5441 (accessed 2001).

Cassileth B.R., Lusk E.J. \& Bodenheimer B.J. (1984) Contemporary unorthodox treatments in cancer medicine. Annals of International Medicine 101, 105-102.

Downer S.M., Cody M.M., McCluskey P., Wilson P.D., Arnott S.J. \& Lister T.A. (1994) Pursuit and practice of complementary therapies by cancer patients receiving conventional medicine. British Medical Journal 309, 86-89.

Eisenberg D.M., Kessler R.C., Foster C., Norlock F.E., Calkins D.R. \& Delbanco T.L. (1993) Unconventional medicine in the United States. New England Journal of Medicine 328, 246-252.

Eng J.L., Monkman D.A., Verhoef M.J., Ramsum D.L. \& Bradbury J. (2001) Canadian cancer society information services: lessons learned about complementary medicine information needs. Chronic Diseases in Canada 22, 102-107.

Ernst E. \& Cassileth B.R. (1998) The prevalence of complementary/alternative medicine in cancer: a systematic review. Cancer 83, 777-782.

Fisher P. \& Ward A. (1994) Complementary medicine in Europe. British Medical Journal 309, 107-111.

Fugh-Berman A. (2000) Herb-drug interactions. Lancet 355, 134138.

House of Lords Science and Technology Select Committee. (2000) Sixth Report Complementary and Alternative Medicine. HL 2000; paper 123 .

Izzo A.A. \& Ernst E. (2001) Interactions between herbal medicines and prescribed drugs: a systematic review. Drugs 61, 2163-3175.

Jellin J.M., Gregory P., Batz F., Bonakdar R. (2003) Pharmacist's Letter/Prescriber's Letter Natural Medicines Comprehensive Database, 5th edn. Therapeutic Research Faculty, Stockton, CA, USA.

MacLennan A.H., Wilson D.H. \& Taylor A.W. (1996) Prevalence and cost of alternative medicine in Australia. Lancet 347, 569573. 
Malassiotis A., Fernadez-Ortega P., Pud D., Ozden G., Scott J.A., Panteli V., Margulies A., Browall M., Magri M., Selvekerova S., Madsen E., Milovics L., Bruyns I., Gudmundsdottir G., Hummerston S., Ahmad A.M-A., Platin N., Kearney N. \& Patiraki E. (2005) Use of complementary and alternative medicine in cancer patients: a European survey. Annals of Oncology 16, 655-663.

Paltiel O., Avitzour M., Peretz T., Cherny N., Kaduri L., Pfeffer R.M., Wagner N. \& Soskolne V. (2001) Determinants of the use of complementary therapies by patients with cancer. Journal of Clinical Oncology 19, 2439-2448.

Rees R., Feigal I., Vickers I., Zollman C., McGurk R. \& Smith C. (2000) Prevalence of complementary therapy use by women with breast cancer: a population-based survey. European Journal of Cancer 36, 1359-1364.
Sollner W., Maislinger S., DeVries A., Steixner E., Rumpold G. \& Lukas P. (2000) Use of complementary and alternative medicine by cancer patients is not associated with perceived distress or poor compliance with standard treatment but with active coping behaviour. American Cancer Society 4, 873-880.

Thomas K.J., Nicholl P. \& Coleman P. (2001) Use and expenditure on complementary medicine in England: a population based survey. Complementary Therapies in Medicine 9, 2-11.

Townsend P., Phillimore P. \& Beattie A. (1988) Health and Deprivation. Inequality and the North. Cross Helm, London, UK.

Werneke U., Earl J., Seydel C., Horn O., Crichton P. \& Fannon D. (2004) Potential health risks of complementary alternative medicines in cancer patients. British Journal of Cancer 90, 408-441. 